\title{
SASSCAL WeatherNet to support regional weather monitoring and climate-related research in Southern Africa
}

\author{
JÖRG HELMSCHROT ${ }^{1}$, GERHARD MUCHE ${ }^{1}$, THOMAS HILLMANN ${ }^{1}$, \\ JOSEPH KANYANGA ${ }^{2}$, MOMPATI BUTALE ${ }^{3}$, DOMINGOS NASCIMENTO ${ }^{4}$, \\ SALOME KRUGER ${ }^{5}$, BEN STROHBACH ${ }^{6}$, MARY SEELY ${ }^{7}$, CARLOS RIBEIRO ${ }^{8}$, \\ WILLEM DE CLERCQ ${ }^{9}$, PIET KENABATHO ${ }^{10}$, KATRIN JOSENHANS ${ }^{1} \&$ \\ NORBERT JÜRGENS ${ }^{1}$ \\ 1 Biodiversity, Evolution and Ecology of Plants (BEE), University of Hamburg, Ohnhorststr. 18, D-22609 Hamburg, Germany \\ joerg.helmschrot@sasscal.org \\ 2 Zambia Meteorological Department (ZMD), PO Box 30200, Lusaka, Zambia \\ 3 Department of Meteorological Services (DMS), PO Box 10100, Gaborone, Botswana \\ 4 Instituto Nacional de Meteorologia e Geofisica (INAMET), Rua 21 de Janeiro, Luanda, Angola \\ 5 National Botanical Research Institute (NBRI), Private Bag 13184, 8 Orban Street, Windhoek, Namibia \\ 6 School of Natural Resources and Spatial Sciences, Polytechnic of Namibia, Private bag 13388, Windhoek, Namibia \\ 7 Gobabeb Research and Training Centre, PO Box 953, Walvis Bay, Namibia \\ 8 Instituto Superior Politécnico Tundaval, Rua Patrice Lumumba, Lubango, Angola \\ 9 Department of Soil Science, Stellenbosch University, Private Bag X1, Matieland, South Africa \\ 10 University of Botswana, Department of Environmental Science, PO Box UB 00704, Gaborone, Botswana
}

\section{INTRODUCTION}

Considering projected climate change and socio-economic development for sub-Saharan Africa, a major challenge in Southern Africa is to secure water at sufficient quality and quantity for both human well-being and the stability of ecosystem functions and services. Many countries of Southern Africa face inadequate monitoring networks to provide reliable data for the development of efficient management strategies for sustainable water and land resources management, drought and flood risk analyses and forecasts, but also climate change impact assessments. For example, in Angola, Botswana and Zambia there is a demand to improve existing national weather monitoring networks in order to provide up-to-date information for decision makers and the public. The Southern African Science Service Centre for Climate Change and Adaptive Land Management (SASSCAL; www.sasscal.org) addresses this deficiency and extends the national monitoring networks in order to provide a consistent and freely accessible data set at regional scale.

\section{SASSCAL INITIATIVE}

As a joint effort of Angola, Botswana, Germany, Namibia, South Africa and Zambia, SASSCAL aims at providing science-based solutions for current problems and future risks in the region. Initially funded by the German Federal Ministry of Education and Research (BMBF), 88 projects of its research portfolio provide information and services allowing for the understanding and assessment of climate and land management change impacts. The main aim of climate-related research is to improve the availability of reliable meteorological baseline data along with a set of analytical methods to strengthen the research capacities in the SASSCAL region, and therewith to support and integrate information on existing national monitoring networks in Southern Africa.

\section{SASSCAL WEATHERNET}

\section{Station network}

Although there is an increasing need for climate data, the number of automatic weather stations (AWSs) in Southern Africa is generally low. To support national efforts by improving their national weather monitoring systems, SASSCAL established a network of AWSs in the partner countries in 2013/14. All stations are equipped with WMO-certified sensors measuring rainfall, temperature, solar radiation, wind speed and direction, relative humidity and barometric pressure, 
optional sunshine duration and leaf moisture. They will be registered for the WMO network by 2015. Embedding the former BIOTA AFRICA network, the SASSCAL WeatherNet comprises currently 87 AWS in the region (Fig. 1). In 2015, the network will be extended by an additional 60 AWS in selected areas of the region. Some of these stations support specific research tasks (experimental networks), but have the same configuration and will be fully integrated.

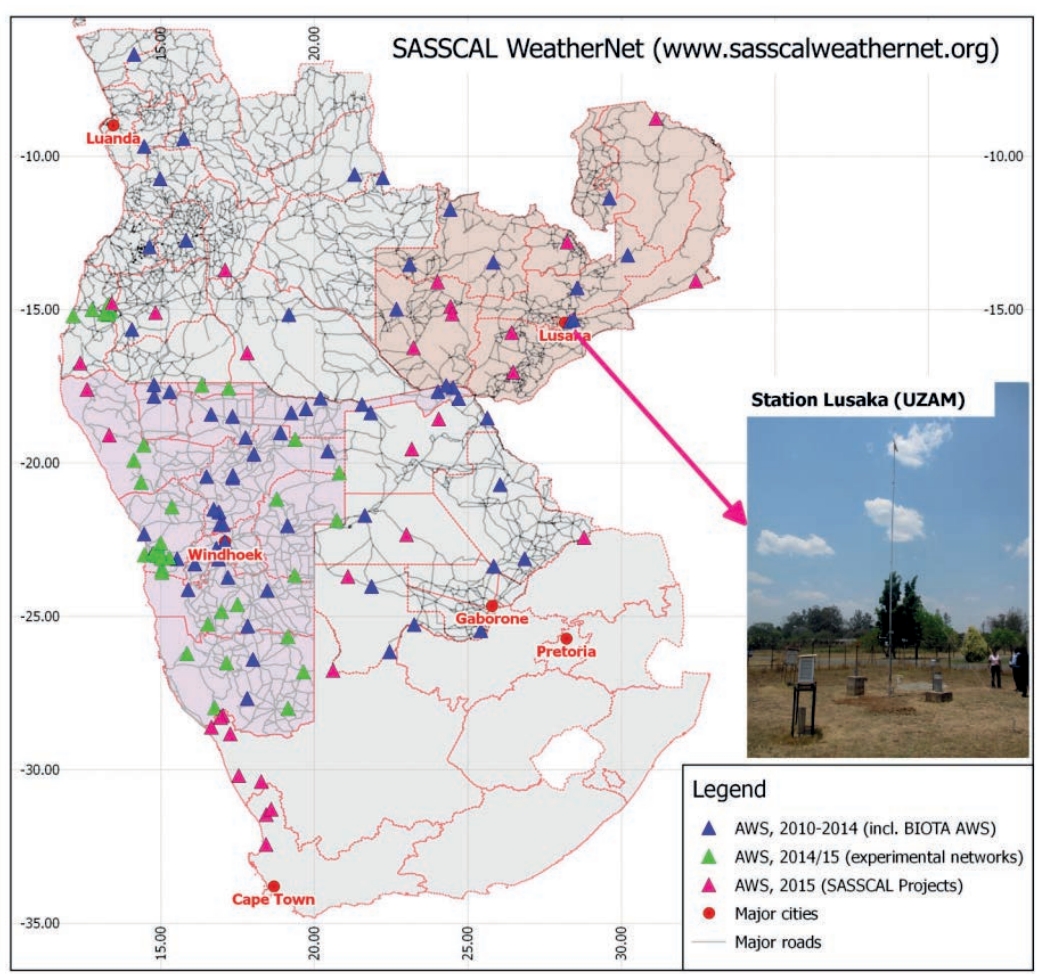

Fig. 1 SASSCAL WeatherNet coverage in the SASSCAL countries (left) and snapshots from the SASSCAL WeatherNet website (right). Note: A local network of five stations set up in the Notwane basin, Botswana, is not yet shown in the map.
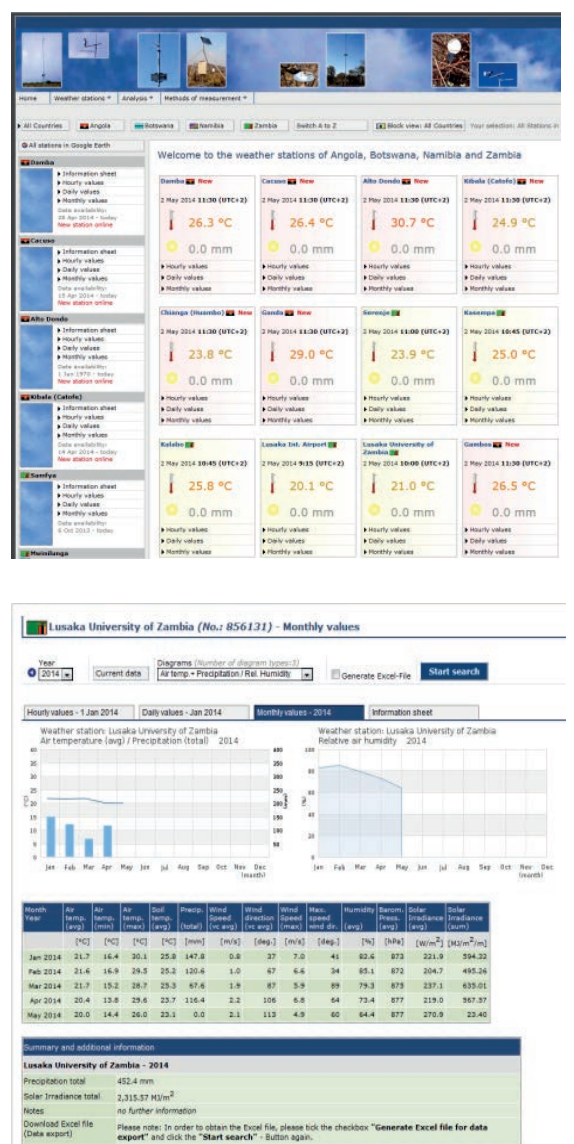

\section{Data availability and access}

Since data transmission from the AWS is based on either GPRS/GSM or satellite transmission, all data is available near-real time to both the national meteorological services and SASSCAL. As part of the SASSCAL mandate of providing regional information as open access, qualitycontrolled and processed data, results are made available freely at the SASSCAL WeatherNet website (www.sasscalweathernet.org). Besides all measured values which are downloadable as continuous time series at 15 or accumulated 60 minutes resolution (partly since 2010), interested users also have the opportunity to receive daily and monthly averages, diagrams for individual parameters as well as station information sheets. In addition, the website provides real-time rainfall information, frost alerts and an option to subscribe for an e-mail-based daily weather report, which is already used by farmers, researchers and governmental institutions.

\section{CONCLUSION AND OUTLOOK}

By the end of 2015, 147 AWS of the SASSCAL WeatherNet will provide accessible near-real time data of major climatological variables and up-to-date statistics for the SASSCAL region. Therewith, SASSCAL, together with collaborating national weather authorities, notably improved the availability of climate information at regional scale, not only for the SASSCAL partners, but also for the general public and decision making authorities. 